Article

\title{
Perception of Urban Trees by Polish Tree Professionals vs. Nonprofessionals
}

\author{
Marzena Suchocka $^{1, *}$, Paweł Jankowski ${ }^{2}$ and Magdalena Błaszczyk ${ }^{1}$ \\ 1 Department of Landscape Architecture, Faculty of Horticulture, Biotechnology and Landscape Architecture, \\ Warsaw University of Life Sciences - SGGW, Ul. Nowoursynowska 159, 02-776 Warsaw, Poland; \\ magdalena_blaszczyk@sggw.pl \\ 2 Department of Econometrics and Statistics, Faculty of Applied Informatics and Mathematics, \\ Warsaw University of Life Sciences - SGGW, Ul. Nowoursynowska 159, 02-776 Warsaw, Poland; \\ pawel_jankowski@sggw.pl \\ * Correspondence: marzena.suchocka@interia.pl; Tel.: +48-506-650-607
}

Received: 1 December 2018; Accepted: 26 December 2018; Published: 3 January 2019

\begin{abstract}
Sustainable urban forests require tree acceptance and support. Two groups of respondents, professionals (working in urban green areas) and individuals (with no professional connection with trees) revealed their attitudes towards trees by assessing statements in a survey questionnaire. Similar general attitude from professionals and nonprofessionals towards the examined benefits and harms related to urban trees was observed. Tree benefits were perceived as much more important than the annoyance they might cause. However, $6 \%$ of nonprofessionals found only negative aspects in trees, proving to be arboriphobes. No arboriphobes and no "Tree sceptics" were among the professionals. Around $40 \%$ of the respondents in the two groups found the number of trees in the surrounding areas too low. The nuisance caused by trees was seen as more disturbing by younger and lower-educated professionals. Women tended to assess trees as more attractive and as having a stronger influence on socioeconomic contributions than men. Men dominated the "Tree indifferent" group. The attractiveness of trees and their impact on socioeconomic contributions were related to the place of residence and the level of education among the nonprofessionals. The level of education of the nonprofessionals was also connected to being clustered into one of the four abovementioned groups of respondents. A majority of medium and big city dwellers as well as a minority of villagers were in the "Tree liking" cluster.
\end{abstract}

Keywords: tree professionals; tree nonprofessionals; attitudes towards trees; perception of trees; sustainable urban development; social survey

\section{Introduction}

Trees are an important part of urban ecosystem as they are environmentally sustainable and economically productive [1]. Urban forest protection plays an important role in enhancing ecosystem services as 'biogenic' or 'green' infrastructure in the process of making livable and sustainable cities. Therefore, to protect urban forest means to preserve and enhance the livability of a city. Sustainable urban forests require a healthy tree and site condition, community-wide tree acceptance and support, but also a comprehensive management approach [2]. Tree professionals should consider how the forest can best meet people's needs [3]. There is considerable and growing literature suggesting that air-pollution mitigation, energy savings, avoidance of runoff, and other benefits are associated with trees [4-6]. The benefits can be estimated, and the monetary value of ecosystem services is the most important and most effective argument supporting tree management. For example, a benefit-cost ratio of 2.83 indicates that the value of projected benefits is nearly three times the value of projected costs [7]. 
On the other hand, it is known, also among professionals, that different values and attitudes can cause social conflict between the need to protect urban trees or to cut them down [1,8,9]. Kirkpatrick [1] points out that trees are not necessarily accepted by all people. People are known to vary considerably in their appreciation of urban forests and green spaces, with attitudes ranging from worship to fear $[10,11]$. This means that professionals need to deal with public pressure to cut trees down, especially when they are in conflict with development, or block out sunlight or the view. People also fear that trees might damage property or cars and should be cut down for sanitary or just personal reasons [12,13]. Hence, it seems very important that professionals take an objective look at the role of trees in the city, free of prejudice and bias.

This problem is also important in Poland, where the landscape architect or arborist profession does not have enough formal and legal support and, therefore, tree protection often depends on their individual decisions. Poland is developing dynamically-similarly to other former socialist members of the EU in Central and Eastern Europe, due to high rates of overcrowded dwellings [14], Poland is undergoing a construction boom. The removal of trees in Polish cities results to a large extent from construction processes and regulations do not contain guidance on technical procedure. Hence, tree protection on construction sites depends on the commitment of professionals and their understanding of the role of trees in the city. Unfortunately, in the design process, a lack of consistent application of tools allowing for the sustainable management of green areas can be observed. That may lead to a decrease of sustainable indicators, such as tree canopy cover and green space, as the percentage of city area (e.g., Siemens Green City Index) $[15,16]$, or indirectly green fabric quota and connectivity of green spaces [17]. More and more often, architects create urban and historic green spaces without proper tree protection, which adversely affects their composition and functions.

To a certain extent, tree professionals are responsible for the successful management and protection of urban forests and must deal with different kinds of constraints. Keeping existing trees in the construction and management process needs the concise environmental and socioeconomic benefits of tree preservation to be successfully communicated to architects and developers [18]. Therefore, it is important to know how professionals perceive the various benefits and harms associated with trees, which can be summarized as (increasing) attractiveness, (improving) social relations and economic value, (causing) nuisance, (being a source of) contamination and damage, and (causing) danger. To assess professionals' understanding of the role of urban forests, it is interesting to compare their attitudes towards trees with the attitudes of a representative group of nonprofessionals.

\subsection{Perceptions of Attractiveness}

City residents appreciate visual and aesthetic benefits [19]. Some tree attributes, such as height, canopy size, and leaf color, or tree characteristics, like higher branching trunks and dense canopy, are the driving factors for a tree's aesthetic quality [20]. City dwellers often express a positive view of street trees, like improvements in the aesthetic environment (sights, sounds, smells) [3]. High importance is assigned by residents to aesthetic and practical attributes, including beautification and the provision of shade [21].

\subsection{Perceptions of Socioeconomic Contrubutions}

Social and economic benefits associated with trees are well known. For example, a large existing tree adds chic and value to properties, which in the case of new projects makes them more readily acceptable by the community, which is especially important for retailers [18]. Psychological benefits associated with physical activity undertaken in urban forests include a sense of community and safety, increased enjoyment of everyday life, a stronger feeling of connection between people and their environment [22] and reduced rates of crime, relief from stress (which can lead to improved physical health), and enhanced feelings and moods [3,23-25]. Social contact is known to have a positive effect on mood and stress levels and an urban forest is a desirable environment in which to undertake it [26]. 


\subsection{Perceptions of Nuisance, Contamination, and Damage}

The cost and inconvenience of urban forests can include nuisance caused by animals, insects, and disease (i.e., Lyme disease or allergies), and displeasure with messiness and clutter [3]. These reasons are a common excuse and cause of felling trees in Poland, especially since the beginning of 2017, when the Polish Act on Environmental Protection liberalized the regulations. Moreover, it is relatively common to find information on trees in conflict with the underground and aboveground infrastructure [27-32]. One of the reasons for the damage comes from the fact that tree roots grow throughout the whole life of the tree and can exert pressure on adjacent soil and nearby infrastructure surfaces [33,34]. This root pressure can lead to, among other things, the lifting of sidewalks $[29,30,35]$ and the widening of pipe cracks [36,37]. The consequent replacement of hardscape elements can cause significant mechanical injury and loss of stability, especially in instances where existing structural roots are severed near the trunk during construction [38].

\subsection{Perceptions of Danger}

Trees can also cause a sense of danger connected with falling trees or limbs [2]. Urban tree risk assessment is a multistage process that is strongly influenced by professional (or nonprofessional) experience, risk perception, and risk tolerance [9]. Likelihood of failure is increased by such factors as tree defects (e.g., decay, poor branch structure) or site factors, like past construction damage in root system or changes in hydrology [39,40]. Perceptions of risk and acceptable risk play key roles in decisions on tree removal, often based on unsubstantiated fear [41] The darkness caused by trees can also lead to a fear of crime [3]. Therefore, the intensity of an urban forest could be considered as a factor in perceptions of safety [41-43].

\subsection{Aim of the Study}

Our study was performed among two groups of respondents: Professionals, i.e., specialists working or planning to work in future on urban green areas; and nonprofessionals, i.e., respondents having no professional connection with trees. We asked both groups about the various benefits and harms associated with trees. The aim of the study was to compare the attitudes of professionals and nonprofessionals towards urban trees. The comparison was performed in two ways. Firstly, we examined the average attitudes towards the examined tree-related benefits and harms in both groups of respondents. Next, the differences in the respondents' attitudes were used to divide both professionals and nonprofessionals into clusters in order to try to identify such groups as arboriphobes or tree enthusiasts. The main goal of this clustering was to estimate and compare the shares of professionals and nonprofessionals in the identified groups. We believe that if professionals are to withstand public pressure to cut trees down, their group should include no arboriphobes and rather include many tree enthusiasts, free from fears and prejudices. On the other hand, it is the professionals who should objectively recognize both the benefits and harms associated with urban trees.

\section{Materials and Methods}

\subsection{Professionals}

Active tree specialists working in the field of planning and construction of building projects as well as possible future specialists were recruited in the years 2015-2016 during the project Roads for Nature on tree diagnostic training in the LIFE project (Project LIFE 11 INF/EN/467 Roads for Nature-a campaign promoting Poland's trees in rural landscapes, as habitats and ecological corridors). The training was designed for current and future design professionals, construction employees, and tree decision-makers, such as public officials. Participants in the meeting were emailed an information letter asking them to fill out the questionnaire, with a link to the survey. Six hundred emails were sent out, for which complete answers were sent back from 198 persons, giving a 21\% response rate. Twelve answers were removed from the study because the respondents had experience 
neither in education concerning tree protection nor in building projects. A further two answers were discarded because the respondents gave the same answers to all the survey questions, leaving 184 answers to the questionnaire analyzed.

Respondents described in our study as professionals represented officials, landscape architects, developers, on field work contractors (builders) and students of landscape architecture. They were persons actively working or planning to work in a field of land use designing, land development, landscaping or urban forest management.

Persons making decisions concerning urban forest management in Polish cities are mainly landscape architects (site design), officials working in city departments of environmental protection (public decision makers), developers, and builders (construction). The specifics of Poland are the role of arborists as performers of care treatments commissioned by the above groups, with only an advisory participation in the decision-making process related to urban greenery. This is mainly due to lack of academic courses in that field in Poland. Another piece of specifics is the high feminization of landscape architecture studies in Poland. For example, at the Warsaw University of Life Sciences (SGGW) landscape architecture course, the highest rated nationwide (according to the Perspektywy ranking [44]), women account for about $80 \%$ of students [45].

The overwhelming majority of the surveyed professional respondents had academic education in landscape architecture and, to a lesser extent, in forestry or civil engineering. Less than $5 \%$ of respondents declared academic education in architecture, spatial planning, environmental protection, agronomy or biology. All respondents had experience regarding urban tree management. Officials included in the survey declared mainly education in landscape architecture, spatial planning and, partially, forestry. Work contractors and developers represented education in landscape architecture or civil engineering. A group of students of the landscape architecture, with completed BSc, participating in the tree diagnostic trainings and continuing MSc studies, was additionally included to the group of tree professionals. The inclusion of students was aimed at broadening the scope of sociodemographic research, such as comparing the attitude of respondents to urban trees, depending on the age and experience.

The professionals were mainly women, aged under 45 years, with higher education, living in cities with more than 200,000 residents. The professionals were divided into four categories: Students, officials, work contractors, and designers. Their detailed sociodemographic characteristics are presented in Table 1.

Table 1. Sociodemographic characteristics of 184 tree planning professionals who responded to a perceptions of urban trees survey in the years 2015-2016 during the project Roads for Nature.

\begin{tabular}{cccccc}
\hline \multirow{3}{*}{ Sex } & Female & $75 \%$ & & Village & $21 \%$ \\
& Male & $25 \%$ & Place of & City below 50,000 citizens & $20 \%$ \\
\multirow{3}{*}{ Age } & Below 30 & $47 \%$ & residence & City 50,000-200,000 citizens & $9 \%$ \\
& $30-45$ & $38 \%$ & & City over 200,000 citizens & $51 \%$ \\
& Over 45 & $15 \%$ & & Village & $8 \%$ \\
\multirow{3}{*}{ Profession } & Student & $31 \%$ & Place of work & City below 50,000 citizens & $18 \%$ \\
& Official & $37 \%$ & & City 50,000-200,000 citizens & $10 \%$ \\
\multirow{2}{*}{ Education } & Work contractor & $15 \%$ & & City over 200,000 citizens & $64 \%$ \\
& Designer & $17 \%$ & Work & Less than 1 year & $15 \%$ \\
& Secondary & $29 \%$ & experience & 1-3 years & $30 \%$ \\
& Higher & $71 \%$ & & O-10 years & $33 \%$ \\
\hline
\end{tabular}

\subsection{Nonprofessionals}

Nonprofessionals were randomly selected Polish citizens who do not take part in the decision-making process concerning urban forest management.

A quota sample of Polish citizens $(n=514)$ took part in a survey conducted by the market and public opinion research IMAS International Institute in April 2015. All the survey data collection was 
done via paper-assisted personal interviewing (PAPI). Qualitative methodology was used; answers to closed questions were listed. The closed questions were prompted (with lists to be read by the respondent). As four respondents returned empty questionnaires, the number of surveys analyzed was 510. The detailed sociodemographic characteristics of the nonprofessionals are presented in Table 2.

Table 2. Sociodemographic characteristics of a quota sample of 510 Polish citizens (nonprofessionals) who responded to a perceptions of urban trees survey conducted by IMAS International Institute in April 2015.

\begin{tabular}{llllll}
\hline \multirow{2}{*}{ Sex } & Female & $52 \%$ & Education & basic/primary & $37 \%$ \\
& Male & $48 \%$ & & secondary and post-secondary & $49 \%$ \\
& Below 30 & $26 \%$ & & Villager & $14 \%$ \\
\multirow{2}{*}{ Age } & $30-45$ & $27 \%$ & \multirow{2}{*}{ Place of residence } & City below 50,000 citizens & $40 \%$ \\
& Over 45 & $46 \%$ & & City 50,000-200,000 citizens & $16 \%$ \\
& & & & City over 200,000 citizens & $19 \%$ \\
\hline
\end{tabular}

\subsection{Questionnaire}

The questionnaires used in the study for both groups of respondents were based on the modified version used in the research conducted by Schroeder et al. [46]. In the case of the professionals, it consisted of 29 statements regarding the benefits and harms associated with urban trees. The respondents expressed their opinion on each of the statements, with answers given on a 5-point Likert scale anchored by "I fully disagree" and "I fully agree". The statements are presented in detail in Table 3. Additionally, the professionals were asked to assess the number of trees in their current place of residence on a 5-point scale anchored by "too few trees" and "a lot of trees". The survey for nonprofessionals was shortened to 24 statements. Each respondent selected those statements with which she/he agreed the most. Additionally, nonprofessionals could choose the statement: "There are too few trees in cities".

\subsection{Statistical Data Analysis}

The agglomerative hierarchical clustering (AHC) with Kendall distance and Ward agglomeration method was used to cluster the survey questions into sets forming the latent variables, based on the professionals' answers. The internal consistency within each set of questions was measured with Cronbach's alpha. For each professional, the values of the latent variables were computed as her/his mean answers to the questions corresponding to each of the variables. The importance of the latent variables for nonprofessionals was estimated by the number of statements belonging to each of the latent variables that they selected. Further analysis of the survey was based on the latent variables. The same clustering method with Euclidian distance was further applied to cluster the respondents, separately professionals and nonprofessionals, based on the latent variables.

The Kruskal-Wallis one-way analysis of variance test was used to compare the median responses to the latent variables among professionals categorized according to each of their sociodemographic characteristics and according to the clusters. In the case of statistically significant differences among the median responses in different categories of respondents, the homogeneous groups of categories were established using the Tukey's honestly significant difference (HSD) multiple comparison procedure.

Contingency tables were created to investigate the relations between the numbers of selected statements associated with the latent variables defined in the study and the sociodemographic features of the nonprofessionals, as well as the dependence of the clusters of professionals and nonprofessionals on their sociodemographic characteristics. The dependence was examined for each of the characteristics with Fisher's exact test [47]. Fisher's exact test was chosen instead of the frequently used chi-square independence test because of the small size of the sample in the study. In the case of significant relations, we applied the approach adopted by Zeiles et al. [48] in order to bring out the pattern of these 
relations. The cells in the contingency table responsible for the departure from independence of the examined variables were identified as those for which the Pearson residual exceeded 1.0, 1.5 and 2.0.

All analyses were performed in the R program version 3.2.5 [49] with the use of RStudio version $0.99 .896[50]$.

\section{Results}

\subsection{Latent Variables Based on Professionals' Answers}

The 29 statements used in the survey were divided via AHC clustering into five sets based on the professionals' answers. Each set of statements could be associated with a latent variable, related to a different general benefit or harm associated with trees. The resulting variables can be described as: "Attractiveness", "Socioeconomic contributions", "Nuisance", "Contamination and damage", and "Danger" (see Table 3). The computed Cronbach's alpha values for the latent variables and the median as well as mean ( \pm standard deviation) answers of the professionals to the latent variables are given in Table 4 . Values of Cronbach's alpha exceeding 0.7 show high reliability of the latent variables. As can be noticed, the two first variables have a positive and a further three negative connotations.

In order to perform a comparison of the perception of urban trees by tree professionals vs. nonprofessionals, the same definition of the latent variables was further applied in the case of the nonprofessionals.

Table 3. Statements from a perceptions of urban trees survey, regarding benefits and harms associated with urban trees, performed in the years 2015-2016 among the tree planning professionals during the project Roads for Nature. Definitions of the latent variables obtained via agglomerative hierarchical clustering (AHC) analysis, related to a different general benefit or harm associated with trees. Indication of statements which appeared in a perceptions of urban trees survey conducted by IMAS International Institute in April 2015 among the quota of Polish citizens (non-professionals).

\begin{tabular}{|c|c|c|}
\hline Statement & Latent Variable & Nonprofessionals \\
\hline "Trees are pleasant to look at" & \multirow{7}{*}{$\begin{array}{l}\text { Attractiveness = "Trees } \\
\text { are attractive and } \\
\text { improve attractiveness of } \\
\text { their surroundings" }\end{array}$} & No \\
\hline "Trees are attractive when bloom" & & No \\
\hline "Trees bring closer the world of nature" & & No \\
\hline "Trees improve aesthetics of the house and surroundings" & & Yes \\
\hline "Trees provide shade" & & No \\
\hline "Trees protect buildings from heat in summer" & & Yes \\
\hline "Trees hide the unpleasant views (such as, e.g., an ugly wall with graffiti)" & & Yes \\
\hline "A positive effect on the feeling of social ties (e.g., with the neighbors)" & \multirow{4}{*}{$\begin{array}{l}\text { Socio-economic } \\
\text { contributions = "Trees } \\
\text { improve social relations } \\
\text { and economical value" }\end{array}$} & No \\
\hline "Trees strengthen the sense of ties with home and family" & & Yes \\
\hline "In areas with trees drivers retain their greater caution and reduces speed" & & Yes \\
\hline "Trees are a source of spiritual and emotional values" & & Yes \\
\hline "Trees are causing economic damage by the roots destructive for pavements" & $\begin{array}{l}\text { Nuisance }=\text { "Trees cause } \\
\text { nuisance" }\end{array}$ & Yes \\
\hline "Trees interfere when their branches grow low from the trunk" & \multirow{4}{*}{$\begin{array}{l}\text { Contamination and } \\
\text { damage = "Trees are } \\
\text { source of contamination } \\
\text { and damage" }\end{array}$} & Yes \\
\hline "Trees litter around with the seeds, dry branches" & & Yes ** \\
\hline "Trees litter the area around, by falling their flowers" & & Yes $* *$ \\
\hline "Trees litter the area around by falling their leaves in the autumn" & & Yes ** \\
\hline "Trees litter the area around when their leaves fall down throughout the summer" & \multirow{6}{*}{$\begin{array}{l}\text { Danger = "Trees cause } \\
\text { danger" }\end{array}$} & Yes ** \\
\hline "Trees are a threat to the security of people because of the brittle branches" & & Yes \\
\hline "Trees reduce visibility and therefore sense of security" & & No \\
\hline "Trees restrict the view from windows of apartments and houses" & & Yes \\
\hline “Trees restrict access of light (shade the area)" & & Yes \\
\hline $\begin{array}{l}\text { "Trees should be removed from playgrounds or along roads, as they constitute a } \\
\text { threat to users" }\end{array}$ & & Yes \\
\hline
\end{tabular}

** Four statements were summarized in one statement: "Trees litter the area around". 
Table 4. Statistical results for the latent variables, related to a different general benefit or harm associated with trees, defined in the study. Left: The Cronbach's alpha values for the latent variables and the median and mean ( \pm standard deviation) answers of the professionals to the latent variables. Right: The importance of the latent variables for nonprofessionals: Overall number of statements belonging to each of the variables chosen by nonprofessionals divided by the numbers of statements included in each variable. Average shares of statements belonging to each of the variables chosen by the respondents. The numbers of respondents who chose at least one statement associated with a given latent variable.

\begin{tabular}{ccccccc}
\hline & \multicolumn{3}{c}{ Responses of Professionals } & \multicolumn{2}{c}{ Importance for Nonprofessionals } \\
\cline { 2 - 6 } & $\begin{array}{c}\text { Cronbach's } \\
\text { Alpha }\end{array}$ & Median & $\begin{array}{c}\text { Mean } \pm \text { Standard } \\
\text { Deviation }\end{array}$ & Overall & $\begin{array}{c}\text { Average } \\
\text { Shares }\end{array}$ & $\begin{array}{c}\text { At Least one } \\
\text { Chosen }\end{array}$ \\
\hline Attractiveness & 0.78 & 4.90 & $4.78 \pm 0.30$ & 227.2 & 0.47 & 460 \\
Socioeconomic benefits & 0.80 & 4.00 & $3.98 \pm 0.78$ & 107.0 & 0.22 & 267 \\
Nuisance & 0.71 & 2.67 & $2.72 \pm 0.95$ & 91.3 & 0.18 & 189 \\
Contamination and damage & 0.91 & 2.33 & $2.32 \pm 0.95$ & 69.7 & 0.14 & 154 \\
Danger & 0.82 & 2.20 & $2.24 \pm 0.80$ & 86.2 & 0.14 & 250 \\
\hline
\end{tabular}

The Kendall tau correlation coefficients of the latent variables are presented in Table 5. According to the results, two groups of variables can be distinguished. First, the "Attractiveness" of trees is positively correlated with "Socioeconomic contributions". Second, "Nuisance", "Contamination and damage", and "Danger" are related to each other. Negative correlations among the variables from the two groups are observed, though not all of them are statistically significant. The factor with significant, negative correlation to both "Attractiveness" and "Socioeconomic contributions" is "Danger".

Table 5. Kendall correlation of latent variables, related to a different general benefit or harm associated with trees, defined in the study. Kendall tau values and corresponding $p$-values given. The statistically significant correlations, at significance level $\alpha=0.05$, highlighted in bold.

\begin{tabular}{ccccc}
\hline & $\begin{array}{c}\text { Socioeconomic } \\
\text { Benefits }\end{array}$ & Nuisance & $\begin{array}{c}\text { Contamination } \\
\text { and Damage }\end{array}$ & Danger \\
\hline Attractiveness & $\mathbf{0 . 4 7 ( < 0 . 0 0 1 )}$ & $-0.03(0.64)$ & $-\mathbf{0 . 1 2}(0.033)$ & $-\mathbf{0 . 2 1}(<0.001)$ \\
Socioeconomic benefits & & $-0.04(0.50)$ & $-0.07(0.19)$ & $-\mathbf{0 . 2 2}(<0.001)$ \\
Nuisance & & & $\mathbf{0 . 3 9}(<0.001)$ & $\mathbf{0 . 2 6}(<0.001)$ \\
Contamination and damage & & & $\mathbf{0 . 4 7}(<0.001)$ \\
\hline
\end{tabular}

\subsection{Nonprofessionals' Choice of Latent Variables}

The importance of the latent variables for nonprofessionals was estimated by the number of statements belonging to each of the latent variables that they chose. Because the numbers of statements belonging to each variable were not equal ( 5 for "Attractiveness", 4 for "Social relations" and "Danger", and 3 for "Nuisance" and "Contamination and damage"), the numbers of statements chosen were divided by the numbers of statements in each variable. The overall results are given in Table 4 . Additionally, Table 4 presents the average shares of statements belonging to each latent variable and numbers of respondents who chose at least one statement associated with a given latent variable.

\subsection{Assessment of the Number of Trees}

Of the professional respondents, $16 \%$ and $26 \%$ assessed that the number of trees in their place of residence is "too low" or "rather too low"; according to $26 \%$ of the professionals, the number of trees is "just right"; $22 \%$ and 10\% assessed that there are "rather a lot of trees" and "a lot of trees", respectively. Finally, 38\% of nonprofessionals chose the statement "there are too few trees in the cities".

\subsection{Arboriphobes}

The lowest answer to the latent variable "Attractiveness" among the examined professionals was 3.6, indicating that there were no arboriphobes in this group of respondents. On the other hand, 
29 nonprofessionals $(6 \%)$ chose none of the statements associated with tree attractiveness. The average respondent in this group chose $0 \%$ of statements related to "Attractiveness", $0 \%$ to "Socioeconomic contributions", 28\% (approximately 1 statement out of 3) to "Nuisance", 34\% (approximately 1 statement out of 3) to "Contamination and damage", and 90\% (between 4 and 5 statements out of 5) to "Danger", respectively, proving that this group contains arboriphobes.

\subsection{Professionals' Answers vs. Social Characteristics}

The results of the comparison of the median answers to the latent variables defined in the study and for the assessment of the number of trees in the place of residence for various sociodemographic groups of professionals are presented in Table 6. Tests show a weak dependence of the answers on the sociodemographic group membership. There was no difference between the examined professions in their attitude towards the five benefits and harms caused by trees. Significantly different median answers were observed between female and male respondents for "Attractiveness" and "Socioeconomic benefits", both of which were scored higher by women. The "Nuisance" caused by trees was assessed differently by respondents of different age, education, and from different places of residence. The nuisance caused by trees, such as allergies or attraction of insects, is on average seen as more disturbing by younger and lower-educated respondents living in the largest cities. The differences in the perception of the "Danger" associated with trees were related to work experience. Professionals with increasing seniority rate "Danger" higher. Finally, the assessment of the number of trees in the place of residence significantly differs only among respondents living in different places of residence, as the residents of villages and the largest cities gave the highest and lowest scores for the number of surrounding trees, respectively.

Table 6. Relation of the latent variables, associated to a different general benefit or harm associated with trees, defined in the study, with the sociodemographic characteristics of the tree planning professionals. Results of the Kruskal-Wallis test followed by the Tukey honestly significant difference (HSD) procedure for the differences between median answers of professionals to the latent variables, and for the assessment of the number of trees in the place of residence in various sociodemographic categories of professionals at significance level $\alpha=0.05$. In the case of significant differences, the mean answers to the latent variables in each sociodemographic category are given, and homogenous groups of categories are denoted with letters.

\begin{tabular}{|c|c|c|c|c|c|}
\hline \multirow[t]{2}{*}{ Sex } & $\begin{array}{l}\text { Female } \\
\text { Male }\end{array}$ & Attractiveness & $\begin{array}{l}4.83 \mathrm{a} \\
4.61 \mathrm{~b}\end{array}$ & $\begin{array}{c}\text { Socioeconomic } \\
\text { contributions }\end{array}$ & $\begin{array}{l}4.08 \mathrm{a} \\
3.70 \mathrm{~b}\end{array}$ \\
\hline & Below 30 & & $2.93 \mathrm{a}$ & & \\
\hline \multirow[t]{2}{*}{ Age } & $30-45$ & Nuisance & $2.59 \mathrm{ab}$ & & \\
\hline & Over 45 & & $2.36 \mathrm{~b}$ & & \\
\hline \multirow{3}{*}{ Education } & Secondary & & $2.93 \mathrm{a}$ & & \\
\hline & Higher & Nuisance & $2.63 \mathrm{~b}$ & & \\
\hline & Village & & $2.48 \mathrm{~b}$ & & $3.34 \mathrm{a}$ \\
\hline \multirow{4}{*}{$\begin{array}{l}\text { Place of } \\
\text { residence }\end{array}$} & City below 50,000 citizens & & $2.63 \mathrm{ab}$ & Number of & $2.81 \mathrm{ab}$ \\
\hline & City $50,000-200,000$ citizens & Nuisance & $2.35 \mathrm{ab}$ & trees & $2.38 \mathrm{ab}$ \\
\hline & City over 200,000 citizens & & $2.91 \mathrm{a}$ & & $2.70 \mathrm{~b}$ \\
\hline & Less than 1 year & & $2.00 \mathrm{~b}$ & & \\
\hline \multirow{3}{*}{$\begin{array}{c}\text { Work } \\
\text { experience }\end{array}$} & $1-3$ years & Danger & $2.15 \mathrm{ab}$ & & \\
\hline & 4-10 years & Danger & $2.24 \mathrm{ab}$ & & \\
\hline & Over 10 years & & $2.53 \mathrm{a}$ & & \\
\hline
\end{tabular}

\subsection{Nonprofessionals' Answers vs. Social Characteristics}

The relations between nonprofessionals' choice of latent variables and their gender, age, education, and place of residence were examined. To simplify the description of the results, the numbers of chosen statements belonging to each of the latent variables were coded in the following way: Low $=0$ or 1 , medium $=2$ or 3 , and high $=4$ or 5 statements in the case of 5 statements; low $=0$ or 1 , medium $=2$, 
and high $=3$ or 4 statements in the case of 4 statements; low $=0$ or 1 , medium $=2$, and high $=3$ statements in the case of 4 statements.

There was no relation between the age and gender of the nonprofessionals and their attitudes toward various tree benefits and harms. As presented in Table 7, significant relations were observed for some of the latent variables and place of residence or education. Education seems to influence nonprofessionals' opinion on both the benefits of trees: Attractiveness, improvement of social relations, and increase of economic value. An increase of the education level increases the percentage of respondents choosing a high number of statements related to the "Attractiveness" and "Socioeconomic contributions" and decreases the percentage of respondents choosing a low number of such statements. Only the opinion on "Contamination and damage" caused by trees is not influenced by the place of residence. In comparison to others, inhabitants of the largest cities seem to select more statements related to "Attractiveness" and a lower number of statements related to "Socioeconomic benefits", "Nuisance", and "Danger". Residents of small cities, with below 50,000 inhabitants, show the least interest in the attractiveness of trees. Finally, in the case of "Danger", the residents of medium size cities, with 51,000-200,000 inhabitants, more often select medium and high numbers of statements related to danger associated with trees. Table 8 presents the significant relations between the selection of the "there are too few trees in the cities" statement and the age and education level of the nonprofessionals (other sociodemographic categories were not significantly related). The results show that the assessment of the number of urban trees varies among respondents of different age and education: Older respondents least often and respondents with higher education most often were of the opinion that the number of trees in cities is not enough.

Table 7. Relation of the latent variables, associated to a different general benefit or harm associated with trees, defined in the study, with the sociodemographic characteristics of nonprofessionals. Results of the Fisher test for the dependence between numbers of the selected statements associated with the latent variables and various sociodemographic categories of nonprofessionals. Nonsignificant differences, at significance level $\alpha=0.1$, denoted by ns. All values in the table given in percentage. The cells in the contingency table responsible for the departure from independence of the examined variables were identified as those for which the Pearson residual exceeded $1.0\left(^{*}\right), 1.5(* *)$, and $2.0\left(^{* * *}\right)$. The numbers in these cells were highlighted in bold.

\begin{tabular}{|c|c|c|c|c|c|c|c|c|c|c|c|c|c|}
\hline & & \multicolumn{3}{|c|}{ Attractiveness } & \multicolumn{3}{|c|}{$\begin{array}{l}\text { Socioeconomic } \\
\text { contributions }\end{array}$} & \multicolumn{3}{|c|}{ Nuisance } & \multicolumn{3}{|c|}{ Danger } \\
\hline & & Low & Medium & High & Low & Medium & High & Low & Medium & High & Low & Medium & High \\
\hline \multirow{5}{*}{$\begin{array}{l}\text { Place of } \\
\text { residence }\end{array}$} & Village & 37 & 40 & 23 & 74 & 15 & $11 *$ & 82 & $14 *$ & $4 *$ & 85 & 9 & 5 \\
\hline & City: $<50 \mathrm{~K}$ & $51 * * *$ & $29 * *$ & 20 & 80 & 12 & 8 & 89 & 11 & $1 * *$ & 89 & 6 & 5 \\
\hline & City: $51-200 \mathrm{~K}$ & 35 & 43 & 23 & 79 & 13 & 8 & 86 & 10 & 5 & $76 *$ & $13 * *$ & $11 * * *$ \\
\hline & City: $>200 \mathrm{~K}$ & $28 * *$ & $46 *$ & 25 & $88^{*}$ & 11 & $1 * * *$ & 92 & 8 & $0 * *$ & & $5 *$ & $0^{* * *}$ \\
\hline & $p$-value & 0.034 & & & 0.048 & & & 0.087 & & & 0.0048 & & \\
\hline \multirow{4}{*}{ Education } & Primary & 42 & 43 & $15 * * *$ & 85 & $10 *$ & $5 *$ & \multirow{4}{*}{$\mathrm{ns}$} & & & \multirow{4}{*}{ ns } & & \\
\hline & Secondary & 38 & 38 & 24 & 77 & 15 & 8 & & & & & & \\
\hline & Higher & $31 *$ & 32 & $38 * * *$ & 69 & 17 & $14^{* *}$ & & & & & & \\
\hline & $p$-value & 0.0050 & & & 0.051 & & & & & & & & \\
\hline
\end{tabular}

Table 8. Results of the Fisher test for the dependence between selecting of the "there are too few trees in the cities" statement and age and education of nonprofessionals. The cells in the contingency table responsible for the departure from independence of the examined variables were identified as those for which the Pearson residual exceeded $1.0\left(^{*}\right), 1.5\left(^{* *}\right)$ and $2.0\left(^{* * *}\right)$. The numbers in these cells were highlighted in bold.

\begin{tabular}{llll}
\hline \multicolumn{4}{c}{ “There are too few trees in the cities" } \\
\hline Age & Selected & Education & Selected \\
Below 30 & $43 \%$ & basic/primary & $34 \%$ \\
$30-45$ & $44 \%$ & secondary and post-secondary & $38 \%$ \\
Over 45 & $33 \% *$ & Higher & $\mathbf{5 0 \%} \%$ \\
$p$-value & 0.041 & $p$-value & 0.065 \\
\hline
\end{tabular}


The small number of arboriphobes did not allow for testing the significance of the differences between their sociodemographic characteristics and the characteristics of the examined quota sample. The majority of the 29 arboriphobes among the nonprofessionals lived in villages (45\%) and cities with below 50,000 citizens ( $48 \%$ ). The division of arboriphobes by gender and age was similar to the division in the quota sample: $48 \%$ female and $52 \%$ male, $24 \%$ below 30 years, $31 \%$ between 30 and 45 years, and $45 \%$ over 45 years of age. There was a higher share of arboriphobes with secondary/post-secondary education than in the quota sample (59\%) and a lower share of arboriphobes with higher education (7\%). Finally, only a minority ( $21 \%$ ) of arboriphobes were of the opinion that the number of trees in cities is too low.

\subsection{Clustering of Professionals}

As no significant differences between the answers to the five latent variables were observed according to the sociodemographic characteristics of the respondents, the answers to the latent variables were used to divide the respondents into clusters. Four clusters of respondents containing $30(16 \%)$, $56(30 \%), 76(41 \%)$, and $22(12 \%)$ persons, respectively, were extracted. The results of the Kruskal-Wallis test followed by the Tukey HSD procedure for the differences between the median answers to the latent variables defined in the study in various clusters are presented in Table 9. The dependence between membership in a given cluster and membership in a given sociodemographic group for each sociodemographic characteristic was assessed with Fisher's exact test for independence. The results of the statistically significant dependencies: Gender, place of work, and assessment of the number of trees in the place of residence, are presented in Table 9. To simplify the description of the results, the answers considering the number of trees were combined, leading to three answers: "Too low" ("rather too low" and "too low"), "just right", and "a lot of trees" ("rather a lot of trees" and "a lot of trees").

Firstly, it can be noticed that though there was a difference in the scores for tree "Attractiveness"-in all clusters, this variable was highly rated. According to the results, the clusters can be divided into two groups. Clusters 1 to 3, all with very high scores for "Attractiveness", contained professionals who additionally rated the influence of urban trees on social relations and increased economic value highly and differed mostly in their recognition of tree-related harms. Cluster 4 was of professionals who rated tree attractiveness highly but significantly lower in comparison to other clusters. The clusters can be characterized in the following way:

- Cluster 1: Tree accepting: The respondents recognizing "Attractiveness" and the positive effect of trees on "Socioeconomic contributions" with high scores for all three tree-related harms. In comparison to clusters 2 and 3, respondents in cluster 1 least often assessed the number of trees in their place of residence as too low. This group could be named "Tree accepting". This group contains a high percentage of respondents working in the largest cities and low share of professionals working in villages.

- Cluster 2: Tree liking: The respondents recognizing "Attractiveness" and the positive effect of trees on "Socioeconomic contributions" with medium scores for all three tree-related harms. This group contains a high percentage of respondents who think that there are too few trees in their place of residence. This group could be named "Tree liking". Cluster 2 contains the highest percentage of women. No respondents working in villages were found in this group.

- Cluster 3: Tree enthusiasts: The respondents recognizing "Attractiveness" and the positive effect of trees on "Socioeconomic contributions" with low scores for all three tree-related harms. Like cluster 2, this group contains a high percentage of respondents who think that there are too few trees in their place of residence. This group could be named "Tree enthusiasts". In comparison to clusters 1 and 2, a high share of respondents working in villages were found in this group.

- Cluster 4: Tree indifferent: The respondents recognizing tree "Attractiveness" with similar, medium scores for all other benefits and harms related to trees. This group contains respondents who seem to have no thought-out opinion about the role of urban trees or whose attitude towards trees is indifferent. This group could be named "Tree indifferent". Cluster 4 consists of respondents 
with an excess of men in comparison to the respondents examined in the survey. This group has a high share of respondents working in villages and smaller cities.

Table 9. Relation of the clusters of tree planning professionals with the latent variables, associated to a different general benefit or harm associated with trees, defined in the study and with the sociodemographic characteristics of the professionals. Upper: Results of the Kruskal-Wallis test followed by the Tukey HSD procedure for the differences between median answers to the latent variables defined in the study in various clusters of respondents at significance level $\alpha=0.5$. In the case of significant differences, the mean answers to the latent variables in each cluster are given and homogenous groups of clusters are denoted with letters. Lower: Results of the Fisher test for the dependence between sociodemographic characteristics and clusters of professionals. Only the significant $(p$-value $<0.1)$ results are presented. The cells in the contingency table responsible for the departure from independence of the examined variables were identified as those for which the Pearson residual exceeded $1.0\left(^{*}\right), 1.5\left(^{* *}\right)$ and $2.0\left(^{* * *}\right)$.

- Cluster 1: Tree accepting: The respondents recognizing "Attractiveness" and the positive effect of trees on "Socioeconomic contributions" with high scores for all three tree-related harms.

- Cluster 2: Tree liking: The respondents recognizing "Attractiveness" and the positive effect of trees on "Socioeconomic contributions" with medium scores for all three tree-related harms.

- Cluster 3: Tree enthusiasts: The respondents recognizing "Attractiveness" and the positive effect of trees on "Socioeconomic contributions" with low scores for all three tree-related harms.

- Cluster 4: Tree indifferent: The respondents recognizing tree "Attractiveness" with similar, medium scores for all other benefits and harms related to trees.

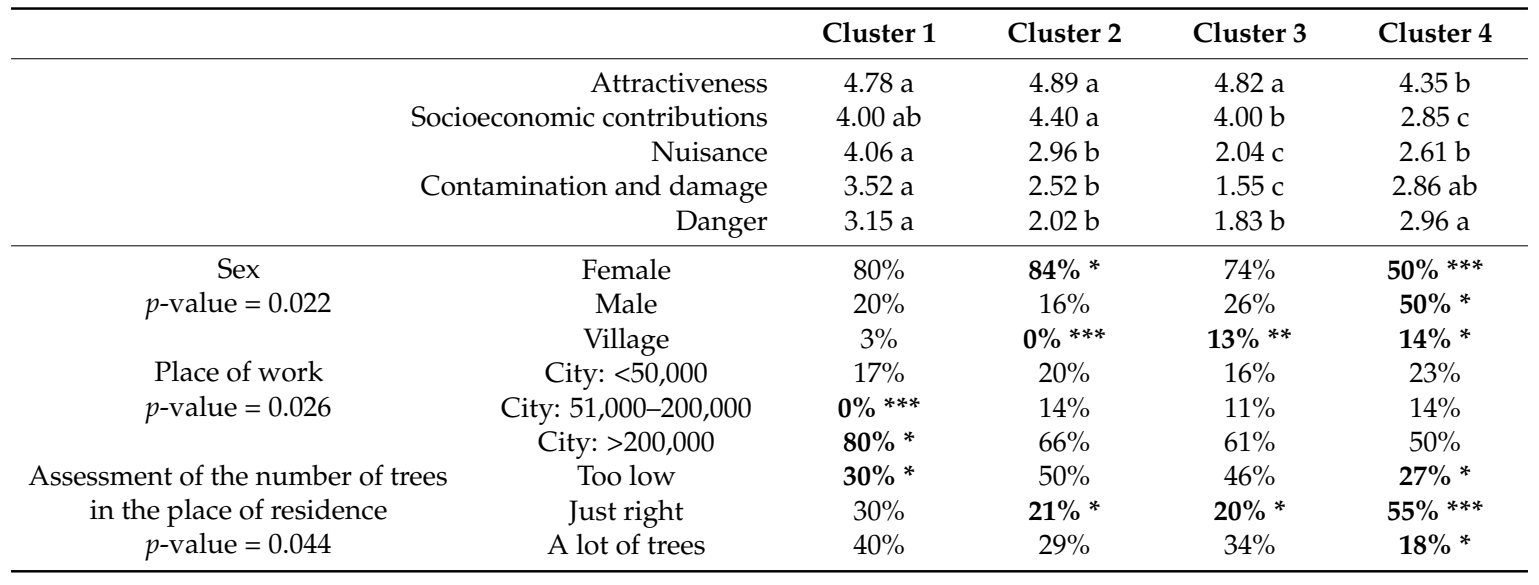

\subsection{Clustering of Nonprofessionals}

Clustering of nonprofessionals was performed after the exclusion of arboriphobes from the set of respondents examined. The division of nonprofessionals into clusters was based on the numbers of chosen statements concerning the five analyzed benefits and harms related to trees and the results are presented in Table 10. Five clusters of respondents containing 64 (13\%), 96 (19\%), 40 (8\%), 16 (3\%), and 265 (52\%) persons, respectively, were extracted. The relation between membership in a given cluster and membership in a given sociodemographic group for each sociodemographic characteristic was assessed with Fisher's exact test for independence. The results of the statistically significant dependencies, for education, place of residence, and assessment of the number of trees in cities, are presented in Table 10. 
Table 10. Relation of the clusters of nonprofessionals with the latent variables, associated to a different general benefit or harm associated with trees, defined in the study and with the sociodemographic characteristics of nonprofessionals. Upper: Average number of selected responses per person in each group of statements divided by the numbers of statements in each group. Lower: Results of the Fisher test for the dependence between sociodemographic characteristics and assessment of the number of trees in the cities and clusters of nonprofessionals (cluster 5 excluded from the last analysis). Only the significant $(p$-value $<0.1)$ results presented. The cells in the contingency table responsible for the departure from independence of the examined variables were identified as those for which the Pearson residual exceeded $1.0\left(^{*}\right), 1.5\left(^{* *}\right)$ and $2.0\left(^{* * *}\right)$.

- Cluster 1: Tree accepting: Respondents who consider trees to be moderately attractive but notice their positive impact on social relations and property value as well as the nuisance related to trees.

- Cluster 2: Tree liking: Respondents who find trees highly attractive but choose very few statements related to other tree benefits and harms.

- $\quad$ Cluster 3: Tree enthusiasts: Respondents who find trees highly attractive, with a high assessment of their impact on socioeconomic benefits.

- $\quad$ Cluster 4: Tree omnibus: Respondents who seem to find all the tree aspects examined in the study important.

- Cluster 5: Tree sceptics: Respondents who were not included into the group of arboriphobes but do not find trees attractive and do not find other benefits and harms related to trees.

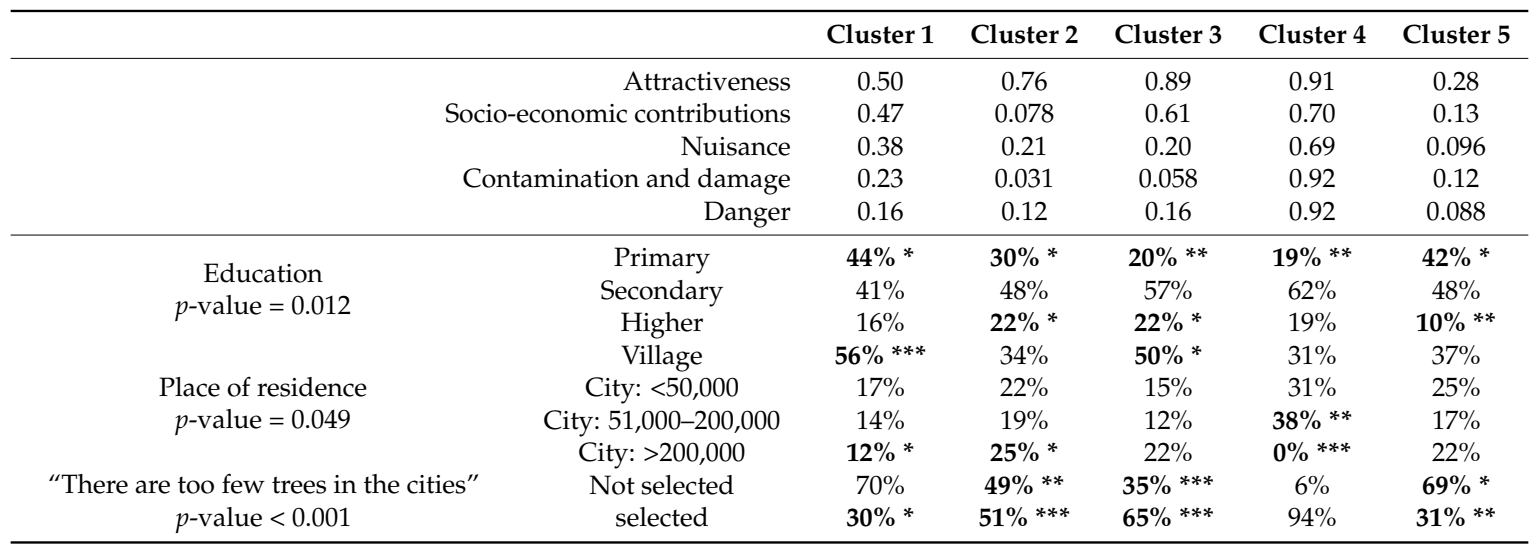

The clusters can be characterized in the following way:

- $\quad$ Cluster 1: Tree accepting: Respondents who consider trees to be moderately attractive but notice their positive impact on social relations and property value as well as the nuisance related to trees. In comparison with clusters 2 and 3, the respondents in cluster 1 more often recognize the contamination and damage caused by trees. Only $30 \%$ of them think that the number of trees in the cities is too low. This group could be named "Tree accepting". This group contains a very high percentage of respondents from villages, and a low number of respondents with higher education.

- Cluster 2: Tree liking: Respondents who find trees highly attractive but choose very few statements related to other tree benefits and harms. These nonprofessionals seem to "just" like trees. About half of them think that the number of trees in the cities is too low. Hence, it seems justified to call this group could "Tree liking". In comparison to other clusters, cluster 2 contains the average percentage of respondents with only primary education and a high share of persons with higher education. This group also contains the highest percentage of respondents from the largest cities.

- Cluster 3: Tree enthusiasts: Respondents who find trees highly attractive, with a high assessment of their impact on socioeconomic benefits. Nearly two-thirds of them think that the number of trees in the cities is too low. This group could be named "Tree enthusiasts". Cluster 3 is dominated by respondents with secondary education. Half of the members of this group live in villages. 
- Cluster 4: Tree omnibus: Respondents who seem to find all the tree aspects examined in the study important. Similarly, all except one person in this group selected the "There are too few trees in the cities" statement. This cluster could be named "Tree omnibus", as its members seem to recognize all benefits and harms related to trees. There are no citizens of the largest cities in this group and, like cluster 3, cluster 4 is dominated by respondents with secondary education.

- Cluster 5: Tree sceptics: Respondents who were not included into the group of arboriphobes but do not find trees attractive and do not find other benefits and harms related to trees. Similarly to cluster 1 , only about $30 \%$ of them think that the number of trees in the cities is too low. This group could be named "Tree sceptics". Also like cluster 1, cluster 5 contains a significantly larger percentage of respondents with only primary education. Among all the clusters, this group contains the lowest share of nonprofessionals with higher education. The respondents in cluster 5 do not stand out due to the place of residence.

\section{Discussion}

The results of the study show a similar general attitude from professionals and nonprofessionals towards the examined benefits and harms related to urban trees. For both groups of respondents, the highest ranked is the benefit of "Attractiveness", followed by the impact of trees on "Socioeconomic contributions". Harm caused by trees seems to be less important. These results agree with the research of Schroeder et al. [46], which showed that the benefits of trees are much more important than the annoyance they cause. Various authors have also shown that the highest ranked benefits were related to tree attractiveness: The ability of trees to provide shade and cool surroundings, followed by trees' influence on helping people to feel calmer [51]; attracting and providing a biodiversity of wildlife [52,53]. This suggests that the aspects of contamination and inconvenience caused by trees have a lower impact on their perception of urban trees and could support conservation of the urban forest.

The negative perception of trees due to the damage that they cause could be further minimized by making the public aware that street trees can potentially reduce the extent of urban infrastructure damage by reducing the need for maintenance of asphalt roadways through shading $[21,54]$ or reduce maintenance costs of underground infrastructure through their interception of rainfall [55].

Still, in the case of nonprofessionals, the difference between the average number of statements selected concerning trees related to the variables "Socioeconomic contributions" versus "Nuisance", "Contamination and damage", and "Danger" seem to be smaller than the analogous difference between the average scores for these variables given by professionals. This may suggest that professionals are more attached to trees than average citizens. As was shown by Lohr et al. [51], respondents who strongly confirmed that trees were important to their quality of life perceived the benefits of trees as higher than those who did not strongly confirm this.

Similar percentages of professionals and nonprofessionals found the number of trees to be too low: $42 \%$ vs. $38 \%$. These numbers cannot be directly compared, as professionals were asked about the number of trees in their place of residence and nonprofessionals could select the statement regarding too few trees in the cities. Still, as the share of questioned nonprofessionals from villages was only $21 \%$, the results suggest small differences between the two groups of respondents in respect to the number of trees around them.

The main difference between the professionals and nonprofessionals examined lies in their division into groups with different relations to trees. No dependence on the represented profession was observed. All the professionals rated tree "Attractiveness" highly. Moreover, there was only one group, containing $12 \%$ of professionals, who did not recognize the influence of trees on "Socioeconomic benefits". As the average scores for each of the tree features apart from "Attractiveness" in this group were close to 3, corresponding to "I neither agree nor disagree with the statement", this group was denoted as "Tree indifferent". Additionally, most of the members of this group believed that the number of trees in their place of residence was just right. The division of the remaining professionals was due 
to a different assessment of the harms related to trees. The three indicated groups of professionals were subjectively denoted as "Tree accepting", "Tree liking", and "Tree enthusiasts". These names result not only from the fact that members of the subsequent groups see the harms related to trees as less and less important. The professionals contained in the first group indicated significantly least often that the number of surrounding trees is too low. Importantly, there were no groups of "tree sceptics" or arboriphobes among the professionals, while such groups were observed among the nonprofessionals. This again supports the conclusion that professionals are more attached to trees than average citizens, which, to some extent, could have been predicted, as practicing this kind of profession is usually consistent with a "pro-nature" approach.

The division of nonprofessionals into groups with different relations to trees is more complicated, as nonprofessionals differ strongly in their assessment of tree "Attractiveness" and the impact of trees on "Socioeconomic contributions". Still, similarly to the professionals, three of the indicated groups of nonprofessionals were subjectively denoted as "Tree accepting", "Tree liking", and "Tree enthusiasts". The main difference between the groups of professionals and nonprofessionals in the groups denoted with the same name is that all of the former rated "Attractiveness" and "Socioeconomic contributions" very highly and, in the case of nonprofessionals, the number of selected statements related to tree "Attractiveness" and "Socioeconomic benefits" increases between the groups. The exception from this scheme is the group of nonprofessionals denoted as "Tree liking", where very few statements related to "Socioeconomic contributions" were selected. As members of this group also selected few statements related to tree harms, this group could also be interpreted as "Tree indifferent". The correctness of the naming of these groups is suggested by the increasing number of respondents selecting the "there are too few trees in the cities" statement. While only 30\% of "Tree accepting" nonprofessionals selected the statement, the corresponding numbers of "Tree liking" and "Tree enthusiasts" increased to 51\% and $65 \%$, respectively. The following group of nonprofessionals, denoted as "Tree omnibus", consisted of nonprofessionals who found all of the statements describing tree benefits and harms important. This may result either from the high estimation of trees by these respondents, supported by the fact that $94 \%$ of them assessed that the number of trees in the cities is too low, or from the fact that these respondents want to prove themselves as experts in the field of ecology. The two remaining groups included the "Tree sceptics" and "Arboriphobes". "Tree sceptics" did not find trees attractive and a minority (31\%) thought that there are not enough trees in the cities. "Arboriphobes" selected none of the statements related to tree-related benefits and only a minority $(21 \%)$ were of the opinion that the number of trees in cities is too low.

A variety of attitudes of urban residents towards trees was also presented in the studies by Kirkpatrick et al. [1,53]. In the study from 2012, respondents were divided into 7 groups ranging from arboriphobes, through indifferent residents, tree huggers, and aesthetes to practical tree lovers and native wildlife lovers. As the division of respondents was based on other questions than in the current study, their results cannot be directly compared. Most interestingly, in the study by Kirkpatrick et al. [1], 13\% of respondents were identified as arboriphobes. Additionally, the study by Kirkpatrick et al. [53] found $0.4 \%$ of respondents who could not agree with anything positive about trees. The ratio of $6 \%$ of arboriphobes among residents identified in the current study falls within the range indicated by the above analysis. Kirkpatrick et al. [1] found also $7 \%$ of indifferent residents. We, on the one hand, found a comparable number of $12 \%$ of tree indifferent specialists, but on the other hand, as many as $52 \%$ of tree sceptics among the nonprofessionals, which is a much higher rate. Finally, the study by Kirkpatrick et al. [53] found that $45 \%$ of residents could be called tree huggers and practical tree lovers, $16 \%$ aesthetes, and $16 \%$ native wildlife lovers. This means that $77 \%$ of the questioned residents declared a positive attitude to urban trees. In the study by Oliveira Fernandes et al. [56], the ratio of the respondents self-reported as tree lovers reached $96 \%$. That result is consistent with the results presented in the current study for the professionals, only $12 \%$ of whom were designated as tree indifferent, but is highly inconsistent with the results for the nonprofessionals, as only $43 \%$ of them were included in one of the groups of "Tree accepting", 
"Tree liking", "Tree enthusiasts" or "Tree omnibus", a fact that can be explained by the too low level of their ecological education.

From the point of view of tree protection, it seems very positive that the numbers of questioned professionals belonging to groups from "Tree accepting" (16\%), through "Tree liking" (30\%) to "Tree enthusiasts" $(41 \%)$ increases, as it shows that for the majority of professionals (71\% contained within the "Tree liking" and "Tree enthusiasts"), recognition of the positive effects of trees prevails over the perception of their negative features. Only the smallest group of about $12 \%$ of respondents comprised professionals who seem to be indifferent towards trees. The fact that, unlike nonprofessionals, the "Tree accepting", "Tree liking" and "Tree enthusiasts" groups of professionals were similar in their assessment of tree "Attractiveness" and "Socioeconomic contributions" may result from two factors: Education and experience. The answers of a professional respondent may be less personal but more objective than those of a nonprofessional. The consequences of decisions made by professionals with a low level of knowledge and a high level of fear could be particularly devastating for urban forests and, for example, result in the removal of veteran, valuable trees deemed unjustifiably as causing risk. In general, as pointed out by Ames and Dewald [18], the most crucial element for tree protection is strong communication between the architect/forester and the constructor, fostered in an environment of respect and cooperation, and is based rather on progress than perfection. Maintaining community involvement is crucial for successful urban tree protection [2], but keeping a high level of professionals' education seems to be even more important for continuity in tree protection policy across generations.

Unfortunately, the number of "Arboriphobes" (6\%) and "Tree sceptics" (52\%) among the nonprofessionals is disturbing, but only small groups of respondents who seem to be concerned about the surrounding trees ( $8 \%$ of "Tree enthusiasts" and 3\% of "Tree omnibus") were identified. However, this result is highly negative for urban forest protection and development, as the important aspect of humans' governance of trees is that it relies on the work of individual city residents and nongovernmental groups. Nongovernmental groups are able to affect street tree design, and self-monitoring of trees by urban residents can support the work of professionals [9]. By contrast, a low level of urban tree tolerance can influence the decision-making process, causing more trees to be felled than is justified.

The low number of Polish respondents who have a positive attitude towards urban trees and the high number of "Arboriphobes" and "Tree sceptics" may result from a low level of ecological education and result in an overestimation of tree-related risks. Kirkpatrick et al. [1] demonstrated that poor education results in a negative attitude toward trees and leads to their felling. As respondents with only primary education are overrepresented in the group of "Tree sceptics", and this group includes the lowest ratio of nonprofessionals with higher education, education regarding the profits resulting from urban forests and the real level of tree-related risks should be emphasized from primary school. All city residents should be made aware that all trees, and especially large trees, contribute to ecosystem services and can benefit human well-being, and that knowledge should be actively promoted [5,57] in the context of climate adaptation strategies, but also regarding individual feelings and emotions bound to the urban forest [58,59].

Some studies have shown that women are more "sensitive" than men in the way they perceive the surrounding landscape. In Kirkpatrick et al.'s study, women dominated the group of "Tree huggers" who loved trees for everything and appreciated them for their spirituality value [52]. Another study demonstrates that women prefer wild, romantic gardens in comparison to men, who prefer them to be regular and well controlled [22,60-62]. In the current study, different assessments of tree features were observed only among the professionals. On average, women found trees slightly more attractive than men did, and women saw the role of trees more strongly as building good social interactions. Additionally, the group of "Tree indifferent" professionals contains an excess of men in comparison to the examined sample of respondents. Since it is women who dominate the group of professionals (in our study they constituted $75 \%$ of the sample), their "sensitive" attitude may have a particular 
influence on decisions towards tree removal or others, which could support the development of city green areas, and eventually the provision of ecosystem services.

In the case of nonprofessionals, "Attractiveness" and "Socioeconomic contributions" were related to the place of residence and education. The level of education was also positively correlated with the attitude to trees: Lower-educated respondents were in the "Tree accepting" cluster, higher in "Tree enthusiast", with "Tree liking" respondents in the middle. Interestingly, respondents in the "Tree liking" cluster were dominated by residents of medium-sized and big cities. By contrast, a minority of villagers participating in the study were assigned to this cluster.

"Nuisance" caused by trees, such as allergies or attraction of insects, is on average seen as more disturbing by younger and lower-educated professionals (these two groups strongly overlap in the present study). This observation can be explained if we assume that younger people are more often victims of allergies, which are a disease of the modern world [63,64], and especially that for them, managing allergies in the context of social relationships could be problematic [65]. In the case of nonprofessionals, "Nuisance" was related only to the place of residence: The statements related to this factor were slightly more often selected by residents of villages and least often by residents of large cities. It is worth noticing, however, that for some city dwellers, the nuisance caused by trees is not seen, since they do not live close to green areas.

In many studies, the increasing age of the respondents had a negative impact on their opinions towards the "Danger" caused by trees $[46,56,66]$. In our study, work experience (to some extent connected with age) was the only variable influencing the perception of "Danger" in the group of professionals: More experienced respondents were more likely to agree with that. This confirms the results of Koeser et al. [9], who found that professional risk assessment and recommended methods of risk mitigation are strongly influenced by experience, i.e., advanced professionals are concerned not only about the fact that a tree may fall but also about a target that the tree may fall over, and therefore rank the risk as higher than professionals and nonprofessionals do. However, in Kirkpatrick's study, the more educated respondents had significantly different opinions on this matter, perceiving a lower level of risk, which could be explained by their ability to evaluate the risks of trees and balance them with advantages [53].

A strong need for education in urban forestry on various social levels follows conclusions from other studies, e.g., that of Oliveira Fernandes [56], who stated that an investment in education and information could lead to conflict mitigation in urban forest management issues. Despot and Gerhold [67] underlined the necessity for educational and marketing efforts to consider property owners, site designers, and construction professionals as crucial to increasing the number of healthy and safe trees in cities. Education, starting from primary school, could be part of the nature-based solutions (NBS) policy concept, community-based decision-making policy or community-based governance models, thereby improving and legitimizing the delivery of ecosystem services (ES) and support challenges associated with climate resilience, health, and well-being in urban areas [68,69].

Interestingly, in our study, the most numerous group among the nonprofessionals stating that the danger caused by trees is low were residents of cities with more than 200,000 inhabitants. By contrast, respondents living in cities with 51,000-200,000 residents were more likely to evaluate the danger as medium or high, which requires further research.

\section{Conclusions}

In conclusion, a similar general attitude from Polish professionals and nonprofessionals towards the examined benefits and harms related to urban trees was observed. For both groups, tree benefits were perceived as much more important than the annoyance they may cause. The main difference between the professionals and nonprofessionals examined lay in their division into groups with different relations to trees. The group of professionals contained no arboriphobes but $41 \%$ of tree enthusiasts. By contrast, the group of nonprofessionals contained $6 \%$ of arboriphobes and, what is most alarming, more than half of them were tree sceptics, while less than $10 \%$ were enthusiastic about 
trees. The above may result from a low level of ecological education and result in an overestimation of tree-related risks. Hence, the major postulated step to increase the ratio of nonprofessionals accepting urban trees and understanding tree-related risks is to increase the level of ecological education, starting from primary school in Poland.

Author Contributions: Conceptualization, M.S.; methodology, P.J., M.S., and M.B.; software, P.J.; validation, M.S., P.J., and M.B.; data curation, MS, P.J.; writing—original draft preparation, P.J.; writing—review and editing, M.S. and M.B.; project administration, M.B.

Funding: This research was partially funded by the Warsaw University of Life Sciences (Young Researcher Grant awarded to Magdalena Błaszczyk).

Acknowledgments: We want to thank the following for their support of this project: Roads for Nature on tree diagnostic training in the LIFE project (Project LIFE 11 INF / EN / 467 Roads for Nature-campaign promoting Poland's trees in rural landscapes, as habitats and ecological corridors) for enabling us conducting the survey among the professionals; Beata Pachnowska and IMAS International Institute for conducting the survey among the nonprofessionals; the reviewers who took their time to shepherd this paper to the point of publication.

Conflicts of Interest: The authors declare no conflict of interest.

\section{References}

1. Kirkpatrick, J.B.; Davison, A.; Daniels, G.D. Sinners, scape goats or fashion victims? Understanding the deaths of trees in the green city. Geoforum 2013, 48, 165-176. [CrossRef]

2. Clark, J.R.; Matheny, N.P.; Cross, G.; Wake, V. A model of urban forest sustainability. J. Arboric. 1997, 23, 17-30.

3. Dwyer, J.; McPherson, E.G.; Schroeder, H.; Rowntree, R. Assessing the benefits and costs of the urban forest. J. Arboric. 1992, 18, 227-234.

4. Nowak, D.J.; Greenfield, J.E. Declining urban and community tree cover in the United States. Urban For. Urban Green. 2018, 32, 32-55. [CrossRef]

5. Ping, S.X.; Yok, T.P.; Edwards, P.; Richards, D. The economic benefits and costs of trees in urban forest stewardship: A systematic review. Urban For. Urban Green. 2018, 29, 162-170. [CrossRef]

6. Maes, J.; Liquete, C.; Teller, A.; Erhard, M.; Paracchini, M.L.; Barredo, J.I.; Grizzetti, B.; Francesca, A.; Somma, F; Petersen, J.E.; et al. An indicator framework for assessing ecosystem services in support of the EU Biodiversity Strategy to 2020. Ecosyst. Serv. 2016, 17, 14-23. [CrossRef]

7. McPherson, E.G.; Grimmond, S.; Souch, C.; Grant, R.; Rowntree, R. Quantifying urban forest structure, function, and value: The Chicago Urban Forest Climate Project. Urban Ecosyst. 1997, 1, 49-61. [CrossRef]

8. Schmied, A.; Pillmann, W. Tree protection legislation in European cities. Urban For. Urban Green. 2003, 2, 115-124. [CrossRef]

9. Koeser, A.K.; Klein, R.W.; Hasing, G.; Northrop, R.J. Factors driving professional and public urban tree risk perception. Urban For. Urban Green. 2015, 14, 968-974. [CrossRef]

10. Chiesura, A. The role of urban parks for the sustainable city. Landsc. Urban Plan. 2004, 68, 129-138. [CrossRef]

11. Skår, M. Forest dear and forest fear: Dwellers' relationships to their neighborhood forest. Landsc. Urban Plan. 2010, 98, 110-116. [CrossRef]

12. Braverman, I. "Everybody loves trees": Policing American cities through street trees. Duke Environ. Law Policy Forum 2008, 19, 81-118.

13. Wilson, J.S.; Lindsey, G.H. Identifying urban neighborhoods for tree canopy restoration through community participation. Plan. Socioecon. Appl. 2009, 1, 29-42.

14. EUROSTAT. Housing Conditions and Housing Deprivation in EU. Data Compilation from EUROSTAT. Available online: http://ec.europa.eu/eurostat/statisticsexplained/index.php/Housing_conditions (accessed on 19 December 2018).

15. Devitofrancesco, A.; Ghellere, M.; Meroni, I.; Modica, M.; Paleari, S.; Zoboli, R. Sustainability assessment of urban areas through a multicriteria decision support system. In Proceedings of the CESB 2016-Central Europe Towards Sustainable Building, Prague, Czech Republic, 22-24 June 2016; Innovations for Sustainable Future. pp. 499-506.

16. Citizen Centric Cities Sustainable Cities Index (SCI) Arcadis. 2016. Available online: https:/ /www.arcadis. com/en/global/our-perspectives/sustainable-cities-index-2016 (accessed on 19 December 2018). 
17. Ghellere, M.; Devitofrancesco, A.; Meroni, I. Urban sustainability assessment of neighborhoods in Lombardy. Energy Proc. 2017, 122, 44-49. [CrossRef]

18. Ames, B.; Dewald, S. Working proactively with developers to preserve urban trees. Cities 2003, 20, 95-100. [CrossRef]

19. Sudipto, R.J.; Pickering, B.C. A systematic quantitative review of urban tree benefits, costs, and assessment methods across cities in different climatic zones. Urban For. Urban Green. 2012, 11, 351-363. [CrossRef]

20. Zhao, J.; Xu, W.; Li, R. Visual preference of trees: The effects of tree attributes and seasons. Urban For. Urban Green. 2017, 25, 19-25. [CrossRef]

21. Mullaney, J.; Lucke, T.; Trueman, S.J. A review of benefits and challenges in growing street trees in paved urban environments. Landsc. Urban Plan. 2015, 134, 157-166. [CrossRef]

22. Bhatti, M.; Church, A. Home, the culture of nature and meanings of gardens in late modernity. Hous. Stud. 2004, 19, 37-51. [CrossRef]

23. Penedo, F.J.; Dahn, J.R. Exercise and well-being: A review of mental and physical health benefits associated with physical activity. Curr. Opin. Psychiatry 2005, 18, 189-193. [CrossRef]

24. Barton, J.; Pretty, J. What is the best dose of nature and green exercise for improving mental health? A multi-study analysis. Environ. Sci. Technol. 2010, 44, 3947-3955. [CrossRef] [PubMed]

25. Day, A.; Scott, N.; Kelloway, K.E. Information and communication technology implications for job stress and employee well-being. Res. Occup. Stress Well Being 2010, 8, 317-350. [CrossRef]

26. Heinrichs, M.; Baumgartner, T.; Kirschbaum, C.; Ehlert, U. Social support and oxytocin interact to suppress cortisol and subjective responses to psychosocial stress. Biol. Psychiatry J. Soc. Biol. Psychiatry 2003, 54, 1389-1398. [CrossRef]

27. Hauer, R.J.; Miller, R.W.; Ouimet, D.M. Street tree decline and construction damage. J. Arboric. 1994, 20, 94-97.

28. McPherson, E.G.; Simpson, J.R.; Peper, P.J.; Scott, K.I.; Xiao, Q. Tree Guidelines for Coastal Southern California Communities; Local Government Commission: Sacramento, CA, USA, 2000; p. 98.

29. Randrup, T.; McPherson, E.R.; Costello, L. Tree root intrusion in sewer systems: Review of extent and costs. J. Infrastruct. Syst. 2001, 7, 26-31. [CrossRef]

30. Grabosky, J.C.; Gilman, E. Measurement and prediction of tree growth reductionfrom tree planting space design in established parking lots. J. Arboric. 2004, 30, 154-155.

31. Celestian, S.B.; Martin, C.A. Effects of parking lot location on size and physiology of four Southwestern U.S. landscape trees. J. Arboric. 2005, 31, 191-197.

32. Day, S.D.; Wiseman, P.E.; Dickinson, S.B.; Harris, J.R. Tree root ecology in the urban environment and implications for a sustainable rhizosphere. Arboric. Urban For. 2010, 36, 193-204.

33. Grabosky, J.C.; Gucunski, N. A Method for simulation of upward root growth pressure in compacted sand. Arboric. Urban For. 2011, 37, 27-34.

34. Dahlhausen, J.; Bibers, P.; Rotzer, T.; Uhl, E.; Pretzsch, H. Tree species and their space requirements in six urban environments worldwide. Forests 2016, 7, 2-20. [CrossRef]

35. D'Amato, N.E.; Sydnor, T.D.; Knee, M.; Hunt, R.; Bishop, B. Which comes first, the root or the crack? J. Arboric. 2002, 28, 277-282.

36. Rolf, K.; Stal, Ö. Tree roots in sewer systems in Malmo, Sweden. J. Arboric. 1994, 20, 329-335.

37. Östberg, J.; Martinsson, M.; Stal, Ö.; Fransso, A. Risk of root intrusion by tree and shrub species into sewer pipes in Swedish urban areas. Urban For. Urban Green. 2012, 11, 65-71. [CrossRef]

38. Smiley, E.T. Root pruning and stability of young willow oak. Arboric. Urban For. 2009, 34, 123-128.

39. Matheny, N.; Clark, J. A Photographic Guide to the Evaluation of Hazard Trees in Urban Areas, 2nd ed.; International Society of Arboriculture: Champaign, IL, USA, 1994; pp. 5-63. ISBN 1-881956-04-0.

40. Kane, B. Tree failure following a windstorm in Brewster, Massachusetts, USA. Urban For. Urban Green. 2008, 7, 15-23. [CrossRef]

41. Moore, G.M. Defining and expanding the urban forest: Opposing unnecessary tree removal requests. In Proceedings of the 15th National Street Tree Symposium, Adelaide, SA, USA, 4-5 Sptember 2014; pp. 70-76.

42. Kuo, F.E.; Bacaioca, M.; Sullivan, W.C. Transforming inner city landscapes: Trees, sense of safety, and preferences. Environ. Behav. 1998, 30, 28-59. [CrossRef]

43. Kuo, F.E.; Sullivan, W.C. Aggression and violence in the inner city: Impacts of the environment via mental fatigue. Environ. Behav. 2001, 33, 543-571. [CrossRef] 
44. Ranking Kierunków Studiów Perspektywy. Available online: http://ranking.perspektywy.org/ 2018/ranking-by-subject/kierunki-rolnicze-lesne-i-weterynaryjne/architektura-krajobrazu (accessed on 19 December 2018).

45. Borczuch, A.; (Administration of Warsaw University of Live Sciences, SGGW, Poland). Personal communication, 2018.

46. Schroeder, H.; Flannigan, J.; Coles, R. Residents' attitudes toward street trees in the UK and U.S. communities. Arboric. Urban For. 2006, 32, 236-246.

47. Fisher, R.A. On the interpretation of $\chi^{2}$ from contingency tables, and the calculation of P. J. R. Stat. Soc. 1922, 85, 87-94. [CrossRef]

48. Zeiles, A.; Meyer, D.; Hornik, K. Residual-based shadings for visualizing (conditional) independence. J. Comput. Graph. Stat. 2007, 16, 507-525. [CrossRef]

49. R Core Team. R: A Language and Environment for Statistical Computing; (Internet https://cran.r-project.org/ doc/manuals/fullrefman.pdf); R Foundation for Statistical Computing: Vienna, Austria, 2016; Available online: http:/ / www.R-project.org/ (accessed on 19 December 2018).

50. Rstudio Team. Rstudio: Integrated Development for R; [Internet]; Rstudio, Inc.: Boston, MA, USA, 2015; Available online: http:/ / www.rstudio.com/ (accessed on 19 December 2018).

51. Lohr, V.I.; Pearson-Mims, C.H.; Goodwin, G.K. Interior plants may improve worker productivity and reduce stress in a windowless environment. Hum. Issues Hortic. Res. 1996, 14, 97-100.

52. Vesely, E.T. Green for green: The perceived value of a quantitative change in the urban tree estate of New Zealand. Ecol. Econ. 2007, 63, 605-615. [CrossRef]

53. Kirkpatrick, J.B.; Davison, A.; Daniels, G.D. Resident attitudes towards trees influence the planting and removal of different types of trees in eastern Australian cities. Landsc. Urban Plan. 2012, 107, 147-158. [CrossRef]

54. McPherson, E.G.; Muchnick, J. Effects of street tree shade on asphalt concrete pavement performance. J. Arboric. 2005, 31, 303-310.

55. McPherson, E.G.; Simpson, J.R.; Peper, P.J.; Maco, S.E.; Xiao, Q.; Mulrean, E. Desert Southwest Community Tree Guide: Benefits, Costs and Strategic Planting; Arizona Community Tree Council, Inc.: Phoenix, AZ, USA, 2004; p. 76.

56. Oliveira Fernandes, C.; Martinho da Silva, I.; Patoilo Teixeira, C.; Costa, L. Between tree lovers and tree haters. Drivers of public perception regarding street trees and its implications on the urban green infrastructure planning. Urban For. Urban Green. 2018. [CrossRef]

57. Shanahan, D.F.; Lin, B.B.; Bush, R.; Gaston, K.J.; Dean, J.H.; Barber, E.; Fuller, R.A. Toward improved public health outcomes from urban nature. Am. J. Public Health 2015, 105, 470-477. [CrossRef] [PubMed]

58. Janse, G.; Konijnendijk, C.C. Communication between science, policy and citizens in public participation in urban forestry-Experiences from the Neighbourwoods project. Urban For. Urban Green. 2007, 6, $23-40$. [CrossRef]

59. Larondelle, N.; Haase, D. Back to nature! Or not? Urban dwellers and their forest in Berlin. Urban Ecosyst. 2017, 20, 1069-1079. [CrossRef]

60. Van den Berg, A.E.; Van Winsum-Westra, M. Manicured, romantic, or wild? The relation between need for structure and preferences for garden styles. Urban For. Urban Green. 2010, 9, 179-186. [CrossRef]

61. Bhatti, M.; Church, A. "I never promised you a rose garden": Gender, leisure and home-making. Leis. Stud. 2000, 19, 183-197. [CrossRef]

62. Dunnett, N.; Qasim, M. Perceived benefits to human well-being of urban gardens. HortTechnology 2000, 10, 40-45. [CrossRef]

63. Lyons, A.C.; Forde, E.M.E. Food allergy in young adults: Perceptions and psychological effects. J. Health Psychol. 2004, 9, 497-504. [CrossRef] [PubMed]

64. Ring, J.; Krämer, U.; Schäfer, T.; Behrendt, H. Why are allergies increasing? Curr. Opin. Immunol. 2001, 13, 701-708. [CrossRef]

65. Worth, A.; Regent, L.; Levy, M.; Ledford, C.; East, M.; Sheikh, A. Living with severe allergy: An Anaphylaxis Campaign national survey of young people. Clin. Transl. Allergy 2013, 3, 2. [CrossRef] [PubMed]

66. Williams, K. Exploring resident preferences for street trees in Melbourne, Australia. J. Arboric. 2002, 28, $161-170$. 
67. Despot, D.; Gerhold, H. Preserving trees in construction projects: Identyfying in centives and barriers. J. Arboric. 2003, 29, 267-280.

68. Raymonda, C.M.; Frantzeskaki, N.; Kabisch, N.; Berry, P.; Breile, M.; Razvan, M.; Geneletti, D.; Calfapietra, C. A framework for assessing and implementing the co-benefits of nature-based solutions in urban areas. Environ. Sci. Policy 2017, 77, 15-24. [CrossRef]

69. Gulsrud, N.M.; Hertzog, K.; Shears, I. Innovative urban forestry governance in Melbourne?: Investigating “green placemaking" as a nature-based solution. Environ. Res. 2018, 161, 158-167. [CrossRef] 